\title{
District nurses' experiences of preventive home visits to 75-year-olds in Stockholm: a qualitative study
}

\author{
Annica Lagerin ${ }^{1}$, Lena Törnkvist ${ }^{2}$ and Ingrid Hylander ${ }^{3}$ \\ ${ }^{1}$ R.N., MSc, PhD candidate, Department of Neurobiology, Care Sciences and Society (NVS), Division of Family Medicine \\ and Academic Primary Health Care Centre, Karolinska Institutet, Alfred Nobels allé 12, S-141 83 Huddinge, Sweden \\ ${ }^{2}$ R.N., Associate Professor, Department of Neurobiology, Care Sciences and Society (NVS), Division of Family Medicine \\ and Academic Primary Health Care Centre, Karolinska Institutet, Alfred Nobels allé 12, S-141 83 Huddinge, Sweden \\ ${ }^{3}$ Associate Professor, Department of Neurobiology, Care Sciences and Society (NVS), Division of Family Medicine and \\ Academic Primary Health Care Centre, Karolinska Institutet, Alfred Nobels allé 12, S-141 83 Huddinge, Sweden
}

\begin{abstract}
Aims: This study had two aims: to describe the dialogue between district nurses (DNs) and older people in preventive home visits (PHVs) from the perspective of the DNs, and to identify barriers to and facilitators of this dialogue as perceived by the DNs. Background: The number of older people is rapidly increasing in all western countries, and as people's age increases, the probability that they will have multiple diseases also increases. Planned actions are therefore needed to promote health and prevent diseases among older people so they can remain in good health and live in their homes for as long as possible. In Sweden, PHVs to 75year-olds by DNs are one such action. Methods: This qualitative study included five group interviews with 20 DNs. Data were analysed with qualitative content analysis. Findings: DNs' experiences of barriers to and facilitators of a successful health dialogue were sorted into five domains. Together, these domains provided a systematic description of the interaction between the DN and the older person in the PHV. The domains included: establishing trustful contact, conducting a structured interview, making an overall assessment, proposing healthpromoting activities and offering follow-up. The barriers and facilitators could be related to the older person, the DN or the home environment. The latent content of the interviews was evident in three themes that were related to the DNs' experiences of barriers and facilitators. These themes illustrated professional dilemmas that the DNs had to resolve to achieve the purpose of the PHV. The study demonstrates that the interaction between a DN and an older person in a PHV can be described as a complex social process in which the DN balances a personal and professional approach, combines a person-oriented and a task-oriented approach and employs both a salutogenic and pathogenic perspective.
\end{abstract}

Key words: 75-year-olds; district nurse; health promotion; preventive home visit; primary health care; qualitative content analysis

Received 10 May 2015; revised 2 October 2015; accepted 2 November 2015;

first published online 1 December 2015

\section{Background}

The number of older people is rapidly increasing in all western countries, and as people's age increases, the probability that they will have multiple diseases also grows (Tinker, 2002; Christensen et al., 2009). Calculations indicate that by $2060,2.7$ million people in Sweden will be older

Correspondence to: Annica Lagerin, R.N., PhD candidate, Department of Neurobiology, Care Sciences and Society (NVS), Division of Family medicineand Academic Primary Health Care Centre, Karolinska Institutet, Alfred Nobels allé 12, S-141 83 Huddinge, Sweden. Email: annica.lagerin@sll.se 
than 65 years $-25 \%$ of the country's population (Sweden Statistics, 2009). According to WHO, all countries in Europe need to prepare for these demographic trends by adapting their health care systems for an ageing population (World Health Organization, 2002). Planned interventions are needed to promote health and prevent diseases among older people so they can remain in good health and live in their homes for as long as possible. In Sweden, preventive home visits (PHVs) to 75-year-olds by district nurses (DNs) are health-promotion interventions that may help achieve these goals (Sherman et al., 2015).

In Sweden, the DN is a well-known kind of specialist nurse working in the primary health care system. Many DNs work at primary health care centres (PHCCs) where they share the responsibility for patient care with family doctors and other health care professionals. Swedish DNs' work includes a broad range of activities, from promoting the health of newborn babies to providing health care for people with chronic conditions. In addition to meeting patients at the PHCC, DNs give home health care to patients living at home (Sherman, 2012). In recent decades, more of the DNs' time than before has been spent caring for older people in their homes as a result of changes in the population structure and the reduction in the number of beds available for older people in hospital wards (Modin and Furhoff, 2002). In addition to providing direct patient care, DNs have an educative role for patients, the goal of which is to help enable people to care for themselves and their family members. In 2006 the Executive Board of the Stockholm County Council decided that DNs should begin making PHVs to 75-year-olds (Sherman et al., 2015). As the main responsibility of DNs is to prevent diseases and promote health in the population, PHVs were regarded as a natural part of the DNs' professional tasks and have been so in the Stockholm County Council area since 2008.

In Stockholm County, a DN contacts each person who has turned 75 and offers that person the opportunity to discuss his or her health and health problems in a structured health dialogue with the DN. DNs in Stockholm take part in a course on health promotion and the methods they should use in PHVs with 75-year-olds (Sherman et al., 2015). The aim of the course is to prepare DNs to (1) identify the older people's health concerns related to their living environment, (2) support self-care activities and empowerment, (3) use a person-centred salutogenic approach, (4) use and evaluate nursing care interventions and (5) document nursing care interventions in accordance with the Well-being-IntegrityPrevention-Safety (VIPS) model. The VIPS model is based on the nursing process and uses key words to provide a structure for nursing documentation (Ehrenberg et al., 1996). During the course, DNs receive a number of documents: an interview guide adapted to the nursing process that includes key words from the VIPS model, literature about health promotion in older people, a template of a letter inviting an older person to a PHV, a list of activities for older people in the neighbourhood and a brochure about safety in the home (Sherman et al., 2015).

Even though the home visits are often called 'preventive', the overall purpose is to conduct health-promoting activities, prevent diseases and assist older people in preserving or restoring body functions (Vass et al., 2007; Lofqvist et al., 2012). The 'salutogenic' perspective is important in the field of health promotion. This perspective focuses on understanding what creates and maintains a person's health rather than what causes disease (Antonovsky, 1996). The focus is placed on finding the determinants that improve health; that is, the determinates that lead to good quality of life. Health dialogues - the key method in all healthpromoting activities, including PHVs - incorporate the salutogenic perspective.

Since 2000, researchers have carried out a number of systematic reviews and meta-analysis is to better understand the effects of PHVs. The results of some of these reviews show that PHVs can decrease hospital admissions (Elkan et al., 2001; Markle-Reid et al., 2006; Huss et al., 2008; Fagerstrom et al., 2009), postpone mortality (Elkan et al., 2001; Stuck et al., 2002; Markle-Reid et al., 2006), reduce costs to society (Stuck et al., 2002; Markle-Reid et al., 2006) and improve physical function (Stuck et al., 2002; Markle-Reid et al., 2006; Huss et al., 2008; Fagerstrom et al., 2009). However, other reviewers conclude that the effects of PHVs are not clear (van Haastregt et al., 2000; Bouman et al., 2008; Mayo-Wilson et al., 2014). This lack of consensus about the effects of PHVs suggests that more research is needed. 
In qualitative studies of older people's experiences of PHVs, participants reported that the visits added to their feelings of safety and helped them preserve their independence (Toien et al., 2014a). Home visitors said that the visits gave them a more positive view of older people, increased their job satisfaction and impacted their professional development (Theander and Edberg, 2005). One qualitative study evaluated a nurse-led programme that included PHVs and subsequent multidisciplinary planning, care and follow-up in general practice (Stijnen et al., 2014). As a result of the programme, proactive care and interdisciplinary collaboration (e.g. with family doctors) improved. However, the researchers concluded that follow-up needed improvement and that to improve follow-up, the professionals needed more time and financial resources (Bleijenberg et al., 2013; Stijnen et al., 2014).

Researchers have emphasised that PHVs include a complex and dynamic social process (Clark, 2001; Liebel et al., 2009; Yamada et al., 2011; Behm et al., 2013a) that cannot be evaluated in the same way as pure medical interventions (Clark, 2001). They have also stressed that qualitative studies investigating the perspectives of the actors in PHVs are needed to gain a deeper understanding of the PHV as a social process (Clark, 2001; Behm et al., 2013b; Toien et al., 2014b). The aim of this deeper understanding is to uncover information that can be used to improve these health-promoting interventions. However, to the best of our knowledge, no study to date describes the communication process - the dialogue between the visitor and the older person that aims to sustain or improve the older person's health and well-being. The first aim of this study was thus to describe the dialogue between DNs and older people in PHVs from the perspective of the DNs. The second was to identify barriers to and facilitators of this dialogue as perceived by the DNs.

\section{Methods}

\section{Study design}

The study had a qualitative descriptive design. Group interviews with DNs (Krueger, 2000) were analysed with qualitative content analysis (Krippendorff, 2004; Elo and Kyngas, 2008). This method of analysis was chosen in order to describe the process in detail from the perspective of DNs.
The group interviews were conducted in the form of a dialogue between the moderator and the DNs about various aspects of DNs' experiences of conducting PHVs with 75-year-olds. Group interviews were chosen as they give the participants the opportunity to provide rich and detailed information about the topics under study (Kvale, 2009) and participants inspire each other to remember incidents and information easily forgotten and therefore often unreported in individual interviews (Krueger, 2000).

\section{Participants and setting}

The study was conducted among DNs who worked at PHCCs in the Stockholm County Council area, which included about two million residents at the time of the study. In 2009, the Stockholm County Council area had five regions, both rural and urban, and a total of 190 PHCCs. To ensure that the DNs in the study had a wide variety of professional experiences, 35 PHCCs from across all five regions were selected. One DN at each of the 35 centres was contacted by telephone and asked to participate in the study. Inclusion criteria were completion of a two-day training program on PHVs for 75-year-olds and having conducted at least five PHVs. A total of 15 DNs withdrew from the study because they were on vacation or sick leave. The remaining $20 \mathrm{DNs}$ (all women) participated in group interviews (two to seven people per group, five groups total) held at three different locations in Stockholm County.

Informed consent was obtained from participants after they received written and oral information on the study and an invitation to a group interview from the first author. The researchers also guaranteed that participants' confidentiality would be preserved when the findings were presented and that participants' involvement was voluntary. The directors of the chosen centres were contacted, their permission to conduct the study was obtained and they were given written details about the study. This study was approved by the Ethics Committee at the Regional Ethics Review Board in Stockholm, Protocol 2009/5:6.

\section{Data collection}

All interviews were moderated by the first author, who has 20 years of nursing experience and is a specialist in district nursing. An observer took 
detailed field notes and wrote down noteworthy quotations in accordance with the methods described by Krueger and Casey (Krueger, 2000). The research group had $>15$ years' experience with qualitative methodology. The moderator used an interview guide with mainly open-ended questions aimed at gathering data to explain and describe the phenomenon (Patton, 2002) and encouraged the participants to talk about experiences of conducting PHVs with 75-year-olds. Examples of questions were: 'What kind of health problems did the 75-year-olds want to discuss?' 'What strategy did you use in order to be able to discuss "health"?' 'Were any issues difficult to discuss?' 'What kind of opportunities and difficulties emerged during these visits?' The sessions were 50 to $60 \mathrm{~min}$ long, audio recorded and transcribed verbatim. After the five group interviews, data became repetitive and redundant, and the researchers estimated that saturation had been achieved.

\section{Data analysis}

Data analysis was conducted using qualitative content analysis, a method well-suited to analysing the sensitive phenomena characteristic of nursing (Elo and Kyngas, 2008). Our approach to qualitative content analyses was based on Graneheim and Lundman, who analyse text in terms of domains, categories, subcategories and themes (Graneheim and Lundman, 2004).

\section{Initial deductive coding into domains}

The transcript of each interview text was first read several times to obtain an overall picture of the DNs' experiences of conducting PHVs with 75-year-olds. Then the text was sorted into content parts (Graneheim and Lundman, 2004) in accordance with five different parts of PHVs hereafter referred to as 'domains'. The domains were created on the basis of the work of Vass et al. (2007) and included establishing trustful contact, conducting a structured interview, making an overall assessment, proposing health-promoting activities and offering follow-up.

Then the text within each domain was divided into meaning units, which were condensed, abstracted and labelled with a code that reflected the manifest content as illustrated by the examples in Table 1. The codes in each domain were grouped into categories and subcategories. At this stage, when the researchers found it necessary, categories and subcategories were moved between domains to ensure meaningfulness and coherence. Throughout the analytical process, subcategories and categories of each domain were compared to verify their relevance. As also described in the literature the categorisation was discussed by the authors until consensus was achieved (Graneheim and Lundman, 2004; Polit and Beck, 2008). At the conclusion of the analytical process, the authors agreed that three themes ran across the domains and categories and revealed underlying latent content in the text.

\section{Results}

The section that follows begins with a description of the dialogue between DNs and older people during PHVs and of barriers to and facilitators of this dialogue. Words in italics refer to subcategories (Table 2). For each domain, one quotation has been provided to illustrate facilitators and one to illustrate barriers. The figure after the quotation means the reference for each extract (e.g. DN 1, DN 2, DN 3, etc.). Finally, the latent content of the interviews is presented in terms of three professional dilemmas that the DNs had to resolve to achieve the purpose of the PHV.

\section{Description of the dialogue between the DNs and older people in the PHVs}

The structure and content of the PHV is presented in five domains, each of which is in accordance with one of the five parts of the PHV that are used to achieve the purpose of the PHV. Both facilitators and barriers affected the DNs' ability to establish trustful contact, conduct a structured interview, make an overall assessment, propose health-promoting activities and offer follow-up. Some facilitators and barriers were related to the older person, others to the $\mathrm{DN}$ and still others to the home environment (Table 2).

\section{Establishing trustful contact}

The DN's first purpose was to establish trustful contact with the older person. Establishing trustful 


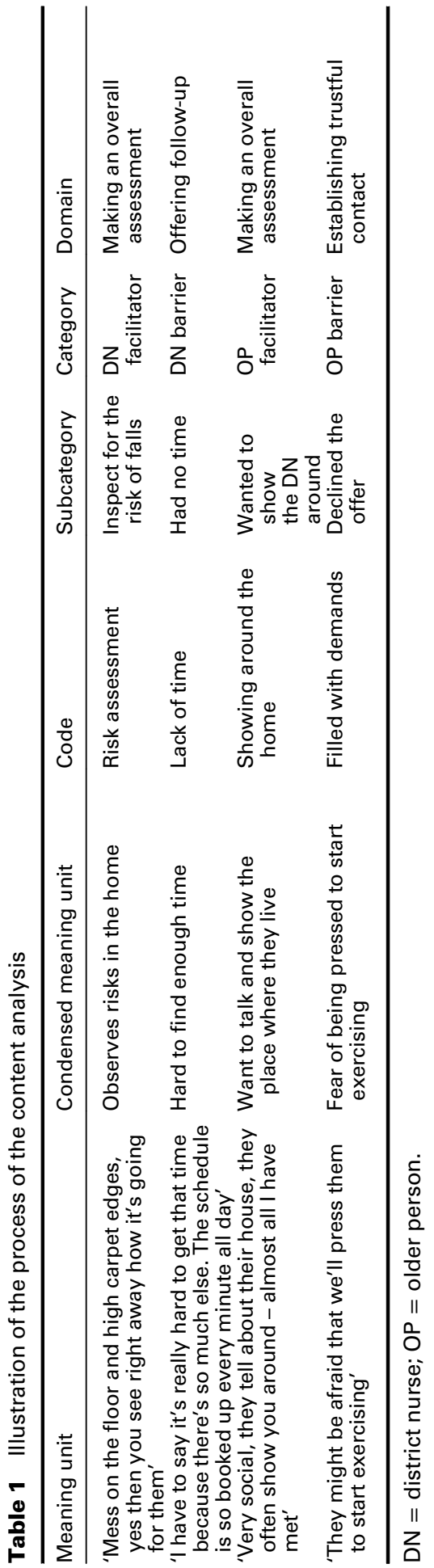

contact means achieving a respectful dialogue in which the older person feels free to bring up his or her concerns with the DN.

Facilitators of establishing trustful contact. The health dialogue between the older person and the DN was generally described as trustful. Establishing trustful contact was facilitated when the older person had confidence in the DN from the start and when the older person talked frankly and openly. The DNs thought that if trustful contact had been established, the older person could bring up delicate issues of great concern, such as grief or problems with the relationship with his or her children. Establishing trustful contact was also facilitated when the DN stayed open both emotionally and intellectually. To stay open, the DNs could decide not to read the person's medical record before the visit or to use the interview guide in a flexible way. As a result of a PHV, the DNs could feel that their relationship with the older person changed. One DN said the older person sometimes felt like a friend:

You get extra deep contact with the person you have had a PHV with. The next time they come to the clinic you feel that you know each other in a completely different way.

(DN 11)

The safe and familiar environment of the home setting also facilitated establishing trustful contact. DNs expressed the opinion that the older person typically perceived his or her home as a peaceful and safe environment for conversations. The DNs thought that a dialogue in the PHV became more personal and was conducted more on the older person's terms than a dialogue at the clinic.

Barriers to establishing trustful contact. When older people declined the offer of a PHV, the DNs thought they had lost an important opportunity to establish trustful contact that would be valuable in future encounters with the older people. DNs also thought that trustful contact was difficult to establish when DN was unfamiliar with the older person's cultural background because of language differences or lack of experience with or knowledge about the person's culture. Feeling pressed for time was also a barrier to attaining trustful contact, as it meant that during the health dialogue, the DNs could not delve into issues as deeply 
Table 2 DN' experiences of facilitators and barriers for the dialogue in preventive home visits, in five domains, related to the older person, the DN and the home environment

\begin{tabular}{|c|c|c|c|c|c|c|}
\hline \multirow[t]{2}{*}{ Domains } & \multicolumn{3}{|l|}{ Facilitators } & \multicolumn{3}{|l|}{ Barriers } \\
\hline & $\mathrm{OP}$ & DN & Home environment & OP & DN & Home environment \\
\hline $\begin{array}{l}\text { Establishing } \\
\text { trustful contact }\end{array}$ & $\begin{array}{l}\text { Confidence in the DN from } \\
\text { the start } \\
\text { Talked frankly and openly }\end{array}$ & $\begin{array}{l}\text { DN stayed open both } \\
\text { emotionally and intellectually }\end{array}$ & $\begin{array}{l}\text { Safe and familiar } \\
\text { environment }\end{array}$ & Declined the offer & $\begin{array}{l}\text { Unfamiliar with OPs } \\
\text { cultural background } \\
\text { Pressed for time }\end{array}$ & $\begin{array}{l}\text { Medical culture } \\
\text { Time-consuming }\end{array}$ \\
\hline $\begin{array}{l}\text { Conducting a } \\
\text { structured } \\
\text { interview }\end{array}$ & $\begin{array}{l}\text { Understood the aims of } \\
\text { the PHV }\end{array}$ & $\begin{array}{l}\text { Used tools: information letter, } \\
\text { interview guide, health index, } \\
\text { medical record, list of drugs, blood } \\
\text { pressure, body mass index, daily } \\
\text { routines }\end{array}$ & Daily routines & Became very quiet & $\begin{array}{l}\text { Felt afraid of } \\
\text { embarrassing }\end{array}$ & $\begin{array}{l}\text { Interventions by } \\
\text { family members }\end{array}$ \\
\hline $\begin{array}{l}\text { Making an overall } \\
\text { assessment }\end{array}$ & $\begin{array}{l}\text { Multifaceted health } \\
\text { dialogue } \\
\text { Wanted to show the DN } \\
\text { around }\end{array}$ & Inspect for the risk of falls & $\begin{array}{l}\text { An overall picture } \\
\text { of the OP's life } \\
\text { situation }\end{array}$ & $\begin{array}{l}\text { Limited the } \\
\text { conversation to } \\
\text { one problem }\end{array}$ & $\begin{array}{l}\text { Difficult to keep } \\
\text { control of the health } \\
\text { dialogue }\end{array}$ & A purely social event \\
\hline $\begin{array}{l}\text { Proposing health- } \\
\text { promoting } \\
\text { activities }\end{array}$ & $\begin{array}{l}\text { Wish for confirmation of } \\
\text { facts and approval of } \\
\text { behaviours }\end{array}$ & The dialogue flowed well & Point out and show & $\begin{array}{l}\text { Was severely ill } \\
\text { Did not } \\
\text { understand the } \\
\text { aims of the visit } \\
\text { Talk only about } \\
\text { medical } \\
\text { problems }\end{array}$ & $\begin{array}{l}\text { Found it difficult to } \\
\text { explain the concept } \\
\text { of health }\end{array}$ & $\begin{array}{l}\text { Interpreter present } \\
\text { during the health } \\
\text { dialogue }\end{array}$ \\
\hline Offering follow-up & Took the initiative & $\begin{array}{l}\text { Phoned } \\
\text { An adequate network }\end{array}$ & $\begin{array}{l}\text { Relatives contacted } \\
\text { the DNs }\end{array}$ & $\begin{array}{l}\text { Did not want to } \\
\text { bother the DNs }\end{array}$ & Had no time & Too many duties \\
\hline
\end{tabular}


as they wished, particularly when serious problems like grief came up. Another barrier was the medical culture at the clinic, which led to the prioritisation of medical duties over health-promotion work. One DN said:

We have also always been used to prioritizing and we must give priority to medical health care efforts.

PHVs were time consuming. DNs estimated that a PHV took an average of $2 \mathrm{~h}: 1 \mathrm{~h}$ for the visit and $1 \mathrm{~h}$ for the trip and documentation, but sometimes it was difficult to finish the visit, travel and finish documentation within that amount of time.

\section{Conducting a structured interview}

Conducting a structured interview involves collecting data about an older person's health, needs, problems, resources and risks.

Facilitators of conducting a structured interview. DNs found it easier to conduct a structured interview when the older person understood the aims of the $P H V$ and understood that the focus was on health instead of disease. One DN said:

It is very varied. Some people don't talk about diseases at all but instead talk about their life. How they are doing well, how seldom they are lonely and the social contacts they have. The picture is very varied.

DNs used tools to facilitate a structured interview. First the DN sent an information letter to the person with an offer of a PHV by the DN. The letter included information about the purpose and goals of a PHV. Most DNs used the interview guide as a basis for the interview and/or had the older person fill out a health index questionnaire. Some DNs prepared themselves by reviewing the person's medical record, including a copy of the list of drugs the older person was taking. If the health dialogue did not start spontaneously at the beginning of the visit, the DN could start by measuring the person's blood pressure or figuring out the person's body mass index. Small talk about daily routines, such as breakfast and daily walks, also facilitated the transition to the structured interview.

Primary Health Care Research \& Development 2016; 17: 464-478
Barriers to conducting a structured interview. Some older people were less talkative than others and became very quiet during the $\mathrm{PHV}$, which was a barrier to conducting a structured interview. Another barrier arose when the DN felt afraid of embarrassing the person or hurting the person's feelings, which is why some DNs did not ask the questions about sexuality that were included in the structured guide. One DN said:

... but I didn't ask about sexuality. I asked a few times when I felt that here now it's okay to bring it up, but for the most part it's really hard.

These DNs considered the subject too personal and difficult to deal with the first time they visited the older person unless the issue (eg, impotence) was taken up by the person himself or herself.

DNs also reported that interventions by family members could be a barrier to conducting a structured interview. Relatives sometimes took over the interview by telling the DN what the older person was unable to do, making remarks about the older person or talking about their own illnesses so that the person who was being interviewed became silent. One DN said:

And when they live together as a couple, I think that it has been a problem, especially if it's the man who is supposed to have the health dialogue, and the wife is there, too. She takes over and explains how he's doing. And she says 'you never listen to what I say, and you never exercise.' She criticizes him the whole time, and it's a little difficult to get her to back off. A few times, I have actually said that maybe now I should primarily talk with your husband while you sit with us and listen because it was getting out of hand and he couldn't get a word in edgewise.

(DN 3)

Barriers to conducting a structured interview that were related to family members could be overcome by the strategy of clarifying to relatives that the health dialogue in the PHV was meant for the older person. Another strategy DNs used was to maintain eye contact with the older person during the dialogue so they felt they were the centre of attention. Some DNs found it beneficial 
Table 3 District nurses' descriptions of somatic, psychological and social problems identified in preventive home visits to 75 -year-olds

\begin{tabular}{|c|c|c|}
\hline Somatic problems & Psychological problems & Social problems \\
\hline $\begin{array}{l}\text { High blood pressure } \\
\text { High blood glucose } \\
\text { Constipation } \\
\text { Ulcers } \\
\text { Overweight } \\
\text { Malnutrition } \\
\text { Swelling of the lower legs } \\
\text { Breathing problems } \\
\text { Impotence } \\
\text { Difficulty walking } \\
\text { Sedentary lifestyle } \\
\text { Alcohol abuse } \\
\text { Tobacco use } \\
\text { Heart problems } \\
\text { Impaired hearing } \\
\text { Reduced appetite } \\
\text { Incontinence } \\
\text { Pain } \\
\text { Diabetes } \\
\text { Dizziness } \\
\text { Stomach pain } \\
\text { Arthritis } \\
\text { Problems with medications }\end{array}$ & $\begin{array}{l}\text { Restlessness/anxiety } \\
\text { Grief } \\
\text { Sleep problems } \\
\text { Memory problems } \\
\text { Loneliness } \\
\text { Unfaithfulness } \\
\text { Low mood } \\
\text { Depression }\end{array}$ & $\begin{array}{l}\text { Forced migration } \\
\text { Few social contacts } \\
\text { Caring for a relative or family member } \\
\text { Relationship problems } \\
\text { Adult children living at home } \\
\text { Need for home modification }\end{array}$ \\
\hline
\end{tabular}

to make a preparatory phone call to inform the older person that the health dialogue in the PHV was personal and that relatives could be included after the dialogue. However, some DNs also felt uncomfortable saying no to a relative who wanted to participate in a health dialogue.

\section{Making an overall assessment}

Making an overall assessment involves analysing the older person's health situation to identify needs, problems and resources.

Facilitators of making an overall assessment. The older person's involvement in a multifaceted health dialogue; that is, the person's wish to talk about many different topics, was a main facilitator of making an overall assessment. DNs stated that most of the older people wanted to talk about health, disease, interests, social networks and eating habits. They also said that many 75-year-olds had more psychosocial problems (such as a grief) rather than somatic problems (such as high blood pressure) (Table 3). One DN said:

... things came up in the dialogue - not physical problems, but maybe more psychological problems or something about their relationship with their partner, wife or husband or problems with loneliness.

(DN 12)

The older person often wanted to show the DN around their home. Experiencing the person's home environment - for example being able to see pictures, furniture and utensils - facilitated the development of an overall picture of the older person's life situation. It was then easier for the DNs to start the conversation by asking about a picture or other small things. It also meant that the DNs got a chance to inspect for the risk of falls, noting the presence of risk factors such as loose power cables or thick carpets.

Barriers to making an overall assessment. It was a serious barrier to making an overall assessment when the older person limited the conversation to one problem. In such cases, the health dialogue tended to take on a solely medical perspective. The DNs then perceived that it was difficult to keep control of the health dialogue and get the person to talk about health issues other than the main

Primary Health Care Research \& Development 2016; 17: 464-478 
problem, which made the overall assessment more difficult. It could also become a serious barrier when the older person wanted to make the PHV into a purely social event with coffee and small talk and the inclusion of family members. One DN said:

In one case it was both the gentleman and lady. They had set the table with coffee and ginger snaps and everything. And then I thought there was a lot of social chit-chat.

(DN 20)

\section{Proposing health-promoting activities}

Promoting health means carrying out or planning measures to improve health and prevent illness and to preserve or restore health and wellbeing.

Facilitators of proposing health-promoting activities. DNs found that the person's need and wish for confirmation of facts and approval of behaviours facilitated their health-promoting work. Many older people sought such confirmation and approval from the DNs, for example regarding support and advice on good eating habits. Health-promoting activities were also facilitated when the dialogue flowed well during the visit. DNs felt that health promotion mainly involved affirming and listening. One DN said:

Yes, I think it feels like they mostly they want to check if they can get my approval, that 'this is what I do, this is what I usually buy, this is how I eat - is it all right?' And I think that it's often very good.

(DN 14)

When the conversation did not flow well, the DNs tried to get the dialogue going by discussing small ailments that hindered the older people in their daily lives instead of real disorders. Furthermore, they discussed things the person could do to experience good health so that the older person would associate the concept of health with positive experiences instead of with medical problems. It facilitated health-promoting activities when the DN had inspected the home for risk of falls and was thus able to point out and show the older person what could be done to increase safety in the home and make life easier.

Primary Health Care Research \& Development 2016; 17: 464-478
Barriers to proposing health-promoting activities. If the older person was severely ill, this could be a barrier to health-promoting activities because the DNs found it hard to describe ideas of health in such circumstances. The DNs also said that some older persons did not understand the aims of the visit and that some wanted to talk only about medical problems. The DN then found it difficult to focus on health and found it difficult to explain the concept of health to the older person. One DN said:

It is also that the health dialogue in the PHV should not focus on diseases but it should be more about how the people perceive their health. But sometimes I have the feeling they may not really understand what it is you mean yet.

(DN 1)

The DNs also reported that having an interpreter present during the health dialogue in the PHV could be a barrier to health-promotion work, as the conversation tended to remain superficial and focus more on problems and diseases than health promotion.

\section{Offering follow-up}

Offering follow-up refers to continuing the nursing care interventions and supporting lifestyle changes.

Facilitators of offering follow-up. Offering followup was facilitated when the older person took the initiative after the home visit to contact the DN about his or her own or spouse's health problems. One DN said:

... it has happened several times that they have like found their way into the health care centre, which they didn't do before, that they didn't know any names. That's a good feeling, and it's, of course, one of the purposes of health dialogues ... establishing contact with the district nurse.

(DN 19)

Some DNs phoned the older person after a PHV and asked if he or she had any concerns, which facilitated offering follow-up either via nursing care visits at home or at the clinic. It also facilitated offering follow-up of the PHV when the DN had a 
basic understanding of social service and rehabilitation options and an adequate network of social service and rehabilitation contacts. An example of offering follow-up facilitated by an adequate network of this kind was meeting the older person's need for home help service or placement in a service home for older people. Occasionally, relatives contacted the DNs with healthcare related questions or requests, such as a request to check blood pressure.

Barriers to offering follow-up. The DNs reported that some older people declined a PHV by a DN because they felt fine, but that another reason some people declined the visit was that they did not want to bother the DNs. In addition, many older people prioritised other things, as they were satisfied with their contact with their family doctor. However, the DNs believed that some people might also have said no because they were afraid that the DN would put pressure on them - for example to start to exercising. The DNs experienced several barriers to offering follow-up, including too many duties at the clinic and the feeling that they simply had no time to offer followup. One DN said:

I have to say it's very hard to get the time because there's so much else. The schedule is so full every minute all day.

(DN 11)

\section{DNs' dilemmas in the PHVs}

The salient finding in the latent content of the interviews was that DNs experienced the home visits as both fulfilling and challenging. Three themes expressed the latent content of the interviews and illustrated DNs' dilemmas in the PHVs.

\section{Balancing a personal approach and a professional approach}

The DNs experienced the home environment as key to the health dialogue because they thought the familiar setting made the older person feel comfortable. The DNs expressed positive surprise that the older people so willingly shared information about their lives. They felt trusted and they felt that the older people showed confidence in them. In addition, when the older person showed the DN around, the DN could easily start the health dialogue by talking or asking about pictures and other small things. It also enabled an overall assessment of the older person's situation and lifestyle habits that could not have been made at the clinic. The DNs thought that a health dialogue in the PHV became more personal and was conducted more on the older person's terms. When the 75-year-olds declined the offer of a PHV, they were instead offered a health dialogue at the clinic. The DNs perceived such health dialogues as more contrived than the PHV and explained that they just saw a little bit of the person's situation and lifestyle habits and the dialogue became much less personal. A clinic visit could also mean distractions by colleagues.

However, participating in a health dialogue in the home environment also posed a dilemma for the nurses, as they were required to find a balance between a personal and a professional approach. For instance, some DNs said that they felt like guests in the older people's homes during health dialogues. They expressed the feeling that through the PHV, they had gotten to know the older people, and the older people had gotten to know them. One said that when she later saw these older people at the clinic, 'they had almost become like my friends' (DN 20).

The DNs sometimes felt that they and the older people became too involved in 'chit-chat' and coffee drinking, and this could shift the focus of the dialogue away from the health of the older person. Moreover, spouses could pose difficulties for DNs. For instance, as already noted, some spouses intervened in a way that the DNs thought shifted the focus of the dialogue away from the older person's health. When such challenges arose, DNs used a variety of strategies to balance the personal and the professional. For example, to stay professional, they could seek eye contact with the 75-year-old to facilitate the dialogue with that person. However, they could also react with flexibility to the wishes of both spouses, for example by informally conducting two health dialogues in one visit. One DN said:

... but I had a woman - we had a health dialogue - who asked if her husband could also participate. Then there were two of them, and it wasn't bad at all; it was really good.

(DN 2) 
The DNs did not directly discuss the dilemma of balancing a personal and a professional approach. Instead, they described the personal relationship that arose as a result of the health dialogue in the home environment as a crucial facilitator of the dialogue.

\section{Balancing a task-oriented and person-oriented approach}

The DNs emphasised the importance of striving for good rapport during the visit and of conducting the conversation on the older person's terms. However, that approach could also cause problems with completing the structured interview and making an overall assessment when the older person wanted to talk about other things. Thus, a factor the DNs experienced as a facilitator in one domain could be experienced as a barrier in another. When the older person talked frankly and openly, this was seen as an important facilitator for establishing trustful contact. However, if the older person talked too openly, the DN might have difficulty, in the limited time available, to follow through in conducting the structured interview and making an overall assessment. DNs sometimes felt that the home visits opened up so many subjects that they did not have time to listen to everything as they would like to have done. Instead they had to interrupt the older person and end the visit or stay longer than they should have. One DN said:

A few times, I've sat two hours, that is, per patient. It's been that they go into different things, and one has a hard time interrupting, and the dialogue has been interesting. But then it has been in connection with the last hour before I finished for the day.

(DN 12)

From the DNs' descriptions of the dialogue, it seemed that the DNs used not only strategies for listening and talking on the older people's terms but also strategies for taking the lead in the interview. Thus, they combined a person-oriented and a task-oriented approach, varying their approach throughout the process of the dialogue in such a way that the person-oriented approach was most salient in the beginning of the dialogue and the task-oriented approach most salient during the structured interview. One DN said:

I always have this interview guide with me, the preprinted template. I think it's very

Primary Health Care Research \& Development 2016; 17: 464-478 good for reining in the dialogue if it goes off on a tangent, which it can do very easily when you discuss something freely. And then I can just get to the next question in a pretty nice way. It's also a help for me. Then I can move on to sleep or pain and I use it to ask my questions in a natural way.

(DN 12)

Balancing a salutogenic and a pathogenic approach

Striving for good rapport could also hinder a health-promoting approach when the older person wanted to talk only about medical problems and the DN was not able to take the lead in the interview and focus on health promotion. On the other hand, many older people had multiple diseases but perceived their health as good despite illness. The DNs reported that most of the 75-year-olds felt their health was good. However, the DNs sometimes discovered illness among the older people through the health dialogue during the $\mathrm{PHV}$; for example, when they checked for high blood pressure or very swollen lower legs.

... though I have been fascinated by this: I take up the health index and you estimate that they feel pretty good, but then it comes up during the health dialogue that they have a lot of pretty serious diseases. Though they still perceive their health as very good.

(DN 13)

This meant that some older people expressed a salutogenic perspective, whereas the DN had to focus on ailments and possible diseases. In other cases, however, the older people did not want to discuss health-promoting activities or did not see the reason for doing so. Instead they wanted to talk about medical problems. In such cases, the DNs tried to reach the health-promotion objective by talking about everyday matters and issues related to the home environment. Thus, the DNs worked to maintain a balance between the salutogenic and the pathogenic perspective.

\section{Discussion}

The interaction between a DN and an older person in a PHV can be described as a complex social process with five domains: establishing trustful contact, conducting a structured interview, making 
an overall assessment, proposing healthpromoting activities and offering follow-up. Three professional dilemmas were evident in the latent content of the interviews with the DNs. To resolve these dilemmas, the DNs had to balance a personal and professional approach, combine a person-oriented and task-oriented approach, and maintain both a salutogenic and a pathogenic perspective.

Trustful contact was crucial in the interaction with the older person and was facilitated by the home environment. The DNs' most striking experience was the older people's willingness to talk openly about their life experiences. The finding that older people appreciated talking about their lives echoes the findings of earlier studies of PHVs (Toien et al., 2014b). Hearing about a person's life can also help the DN see the person behind the illness or disability (Clark, 2001). The home environment and the older people's openness could also constitute a challenge for the DN. The DNs wanted to encourage openness, but one important barrier to openness identified in the current study was time pressure caused by the work situation at the clinic. This barrier sometimes prevented DNs from getting as deeply involved in health dialogues as they wished. Previous studies have also cited lack of time as an important barrier to providing structured care to older people in primary care (Bleijenberg et al., 2013; Stijnen et al., 2014). Moreover, if DNs felt treated as personal friends, they could be hampered in their goal of making an overall assessment and conducting a structured interview. This balance between being personal and professional has been described in other professional care situations that take place in the private sphere (Karlsson et al., 2009). An earlier study has shown that home care assistants had to balance actual care needs and patients' expressed needs; they needed to be professional (but not too distant) and personal (but not too personal) (Swedberg et al., 2013). Furthermore, other researchers have described the situation of people who do public work in a private domain as 'being in an intermediate position' (Martin Matthews, 2008).

The DNs explained that they maintained an open mind and listened attentively to make sure the dialogue took place on the older person's terms. They strived to respect and affirm the person's experience, confirm the person's interpretation of illness and disease and promote health on the basis of the person's interpretation. Such a person-centred approach is considered a fundamental part of person-centred nursing and a key to successful care outcomes (McCormack, 2004). However, the person-centred approach sometimes did not go as planned. If the DN did not take sufficient leadership of the health dialogue, important objectives of the dialogue might not be achieved. A combination of a person-oriented and a task-oriented approach seemed to work best. At the outset of the PHV, the social process could be described as predominantly person-oriented. Once trustful contact had been established and the dialogue was underway, task-orientation became more prominent. Earlier studies on PHVs have also found that it is necessary to initially establish a trusting relationship in order to initiate a health dialogue on needs and health resources. This trusting relationship is also necessary for conducting successful health-promoting work later on (Toien et al., 2014b). The findings of the current study also suggest that a patient-centred approach must include flexibility in the core content of the PHV, as the needs of 75-year-olds vary immensely. Thus, the home visitor must have good communication skills and exhibit professionalism (Yamada et al., 2011), but his or her advice regarding practical actions must also suit the older person's daily life (Vass et al., 2007; Toien et al., 2014a).

In line with Antonovsky's salutogenic approach, health promotion is a key concept in the PHV (Antonovsky, 1996), and indeed, the DNs in this study described the medical culture at the clinic as a critical barrier to conducting PHVs. The DNs were, however, surprised to discover that many older people experienced good health despite illness, thus showing an apparently salutogenic focus. This finding echoes the results of another study in which researchers found that serious diseases in people over the age of 60 did not always lead to reduced self-assessed quality of life (Solomon et al., 2010). However, according to the DNs, not all of the older people seemed to have a salutogenic focus. Some only wanted to talk about medical symptoms. A Norwegian study also found that the concepts of health promotion and disease prevention interventions could be difficult for older people to comprehend (Toien et al., 2014b), and difficulty comprehending these concepts may 
influence adherence to health advice and the effects of PHVs. The present study also showed that DNs sometimes used medical records, lists of medication and assessment of blood pressure to start a structured interview; that is, tools related to medical care and prevention rather than to health promotion. Thus, when older people only talked about their diseases, the DNs had to add a salutogenic perspective. However, when the older people just said that they felt fine, the DNs sometimes had to work to identify medical symptoms to fulfil the goal of the PHV. The results of this study thus suggest that PHVs incorporate both health promotion and disease prevention; that is, both a salutogenic and a pathogenic perspective, which is in line with the findings of the Norwegian study (Toien et al., 2014b).

Implementation of new methods such as PHVs is a complex process. It is affected by many factors, not only at the individual level but also at the organisational level, such as organisation of care and leadership (Grol and Grimshaw, 2003). Time and management involvement are needed to create conditions that support the DNs in resolving their professional dilemmas so they can better achieve the purpose of PHVs.

\section{Methodological considerations}

The researchers involved in this study considered qualitative group interviews to be the appropriate method of gathering data to achieve the aim of this study. In the group interviews, all DNs had the opportunity to express their opinions regarding their experiences of conducting PHVs with 75 -year-olds. The $20 \mathrm{DNs}$ who participated in the study represented a wide variety of experiences of PHVs and had long professional experience as DNs. The first author is a DN familiar with PHVs to older people, which facilitated the monitoring of the group interviews but on the other hand might have led to bias in interpreting data. The co-authors therefore continuously discussed the analysis and the results until they reached agreement. The results and interpretations have also been discussed at several academic seminars.

\section{Implications for health care and research}

The study demonstrates that, the interaction between a DN and an older person in a PHV can

Primary Health Care Research \& Development 2016; 17: 464-478 be described as a complex social process, in which DN balances a personal and professional approach, combines a person-oriented and a taskoriented approach and employs both a salutogenic and pathogenic perspective. Training is needed for such a professional process, or the PHV may become either too informal and personal or too structured and formal. This study indicated that a person-oriented approach is typically in some parts of a PHV, and a task-oriented approach in others. Moreover, DNs must focus more on the salutogenic perspective with some people and the pathogenic perspective with others. More research is necessary to scrutinise DNs' strategies for maintaining the necessary balance and for combining perspectives. The perspective of the older people must also be studied to better understand and improve the process.

\section{Conclusions}

The main results of this study are the systematic description of the five domains of the PHV, the DNs' perspectives on facilitators of and barriers to a successful health dialogue, and the description of the three major dilemmas faced by DNs in PHVs. The barriers, facilitators and dilemmas identified in this study may form a helpful basis for improving the training of DNs who conduct PHVs and may facilitate further development of these healthpromotion interventions for older people.

\section{Acknowledgements}

The authors thank the district nurses who participated in this study. The authors thank Scientific Editor Kimberly Kane for useful comments on the text.

\section{Conflicts of Interest}

The authors declare that there are no conflicts of interest.

\section{Ethical Standards}

The authors assert that all procedures contributing to this work comply with the ethical standards of relevant national and institutional guidelines and with the Helsinki Declaration of 1975 , as revised in 2008 . 


\section{References}

Antonovsky, A. 1996: The salutogenic model as a theory to guide health promotion. Health Promotion International 11, 11-18.

Behm, L., Ivanoff, S.D. and Ziden, L. 2013a: Preventive home visits and health - experiences among very old people. BMC Public Health 13, 1-10.

Behm, L., Ziden, L., Duner, A., Falk, K. and Dahlin-Ivanoff, S. 2013b: Multi-professional and multi-dimensional group education - a key to action in elderly persons. Disability and Rehabilitation 35, 427-35.

Bleijenberg, N., Ten Dam, V.H., Steunenberg, B., Drubbel, I., Numans, M.E., De Wit, N.J. and Schuurmans, M.J. 2013: Exploring the expectations, needs and experiences of general practitioners and nurses towards a proactive and structured care programme for frail older patients: a mixed-methods study. Journal of Advanced Nursing 69, 2262-73.

Bouman, A., Van Rossum, E., Ambergen, T., Kempen, G. and Knipschild, P. 2008: Effects of a home visiting program for older people with poor health status: a randomized, clinical trial in the Netherlands. Journal of the American Geriatrics Society 56, 397-404.

Christensen, K., Doblhammer, G., Rau, R. and Vaupel, J.W. 2009: Ageing populations: the challenges ahead. Lancet 374, 1196-208.

Clark, J. 2001: Preventive home visits to elderly people. Their effectiveness cannot be judged by randomised controlled trials. BMJ 323, 708.

Ehrenberg, A., Ehnfors, M. and Thorell-Ekstrand, I. 1996: Nursing documentation in patient records: experience of the use of the VIPS model. Journal of Advanced Nursing 24, 853-67.

Elkan, R., Kendrick, D., Dewey, M., Hewitt, M., Robinson, J., Blair, M., Williams, D. and Brummell, K. 2001: Effectiveness of home based support for older people: systematic review and meta-analysis. BMJ 323, 719-25.

Elo, S. and Kyngas, H. 2008: The qualitative content analysis process. Journal of Advanced Nursing 62, 107-15.

Fagerstrom, L., Wikblad, A. and Nilsson, J. 2009: An integrative research review of preventive home visits among older people-is an individual health resource perspective a vision or a reality? Scandinavian Journal of Caring Sciences 23, 558-68.

Graneheim, U. and Lundman, B. 2004: Qualitative content analysis in nursing research: concepts, procedures and measures to achieve trustworthiness. Nurse Education Today 24, 105-12.

Grol, R. and Grimshaw, J. 2003: From best evidence to best practice: effective implementation of change in patients' care. Lancet 362, 1225-30.

Huss, A., Stuck, A.E., Rubenstein, L.Z., Egger, M. and CloughGorr, K.M. 2008: Multidimensional preventive home visit programs for community-dwelling older adults: a systematic review and meta-analysis of randomized controlled trials.
The Journals of Gerontology. Series A, Biological Sciences and Medical Sciences 63, 298-307.

Karlsson, I., Ekman, S.L. and Fagerberg, I. 2009: A difficult mission to work as a nurse in a residential care home-some registered nurses' experiences of their work situation. Scandinavian Journal of Caring Sciences 23, 265-73.

Krippendorff, K. 2004: Content analysis: an introduction to its methodology. Califonia: Sage Publications.

Krueger, R. and Casey, A. 2000: Focus groups: a practical guide for applied research. Thousand Oaks, CA: Sage Publications.

Kvale, S. 2009: InterViews: learning the craft of qualitative research interviewing. Los Angeles: Sage Publications.

Liebel, D.V., Friedman, B., Watson, N.M. and Powers, B.A. 2009: Review of nurse home visiting interventions for community-dwelling older persons with existing disability. Medical Care Research and Review 66, 119-46.

Lofqvist, C., Eriksson, S., Svensson, T. and Iwarsson, S. 2012: First steps towards evidence-based preventive home visits: experiences gathered in a Swedish municipality. Journal of Aging Research 2012, 352942.

Markle-Reid, M., Browne, G., Weir, R., Gafni, A., Roberts, J. and Henderson, S.R. 2006: The effectiveness and efficiency of home-based nursing health promotion for older people: a review of the literature. Medical Care Research and Review 63, 531-69.

Martin Matthews, A. and Phillips, J. 2008: Aging and caring at the intersection of work and home life: blurring the boundaries. New York: Lawrence Erlbaum Associates/ Psychology Press.

Mayo-Wilson, E., Grant, S., Burton, J., Parsons, A., Underhill, K. and Montgomery, P. 2014: Preventive home visits for mortality, morbidity, and institutionalization in older adults: a systematic review and meta-analysis. PLoS One 9, e89257.

Mccormack, B. 2004: Person-centredness in gerontological nursing: an overview of the literature. Journal of Clinical Nursing 13, 31-38.

Modin, S. and Furhoff, A.K. 2002: Care by general practitioners and district nurses of patients receiving home nursing: a study from suburban Stockholm. Scandinavian Journal of Primary Health Care 20, 208-12.

Patton, M.Q. 2002: Qualitative research \& evaluation methods. Third edition. London: Sage.

Polit, D.F. and Beck, C.T. 2008: Nursing research: generating and assessing evidence for nursing practice. Philadelphia: Wolters Kluwer Health/Lippincott Williams \& Wilkins.

Sherman, H. 2012: Preventive home visits för 75-year-old persons by the district nurses. Licentiate degree, Stockholm: Karolinska Institute.

Sherman, H., Soderhielm-Blid, S., Forsberg, C., Karp, A. and Tornkvist, L. 2015: Effects of preventive home visits by district nurses on self-reported health of 75-year-olds. Primary Health Care Research \& Development Jan 26, 1-16.

Solomon, R., Kirwin, P., Van Ness, P.H., O'leary, J. and Fried, T.R. 2010: Trajectories of quality of life in older persons with

Primary Health Care Research \& Development 2016; 17: 464-478 
advanced illness. Journal of the American Geriatrics Society $58,837-43$.

Stijnen, M.M., Jansen, M.W., Duimel-Peeters, I.G. and Vrijhoef, H.J. 2014: Nurse-led home visitation programme to improve health-related quality of life and reduce disability among potentially frail community-dwelling older people in general practice: a theory-based process evaluation. BMC Family Practice 15, 173.

Stuck, A.E., Egger, M., Hammer, A., Minder, C.E. and Beck, J.C. 2002: Home visits to prevent nursing home admission and functional decline in elderly people: systematic review and meta-regression analysis. JAMA: The Journal of the American Medical Association 287, 1022-28.

Swedberg, L., Chiriac, E.H., Tornkvist, L. and Hylander, I. 2013: From risky to safer home care: health care assistants striving to overcome a lack of training, supervision, and support. International Journal of Qualitative Studies on Health and Well-Being 8, 20758.

Sweden Statistics. 2009: Sveriges framtida befolkning 2009-2060 (Sweden's future population 2009-2060). Stockholm: Statistiska centralbyrån (SCB) Retrieved 10 November 2014 from http://www.scb.se/statistik/_publikationer/BE0401_2009I60_ BR_BE51BR0901.pdf

Theander, E. and Edberg, A. 2005: Preventive home visits to older people in Southern Sweden. Scandinavian Journal of Public Health 33, 392-400.
Tinker, A. 2002: The social implications of an ageing population. Mechanisms of Ageing and Development 123, 729-35.

Toien, M., Bjork, I.T. and Fagerstrom, L. 2014a: Older users' perspectives on the benefits of preventive home visits. Qualitative Health Research 25, 700-12.

Toien, M., Heggelund, M. and Fagerstrom, L. 2014b: How do older persons understand the purpose and relevance of preventive home visits? A study of experiences after a first visit. Nursing Research and Practice, 2014, 640583.

Van Haastregt, J., Diederiks, J., Van Rossum, E., De Witte, L. and Crebolder, H. 2000: Effects of preventive home visits to elderly people living in the community: systematic review. BMJ 320, 754-58.

Vass, M., Avlund, K., Hendriksen, C., Philipson, L. and Riis, P. 2007: Preventive home visits to older people in Denmarkwhy, how, by whom, and when? Zeitschrift fur Gerontologie und Geriatrie 40, 209-16.

World Health Organization. 2002: Active aging: a policy framework. Madrid: World Health Organization. Retrieved 12 June 2015 from http://www.who.int/ageing/publications/ active_ageing/en/.

Yamada, Y., Vass, M., Hvas, L., Igarashi, A., Hendriksen, C. and Avlund, K. 2011: Collaborative relationship in preventive home visits to older people. International Journal of Older People Nursing 6, 33-40. 